\title{
Cancer incidence attributable to the use of oral contraceptives and hormone therapy in Alberta in 2012
}

\author{
Xin Grevers MSc, Anne Grundy PhD, Abbey E. Poirier MSc, Farah Khandwala MSc, Matthew Feldman MPH, \\ Christine M. Friedenreich PhD, Darren R. Brenner PhD
}

See also www.cmajopen.ca/lookup/doi/10.9778/cmajo.20150068

\section{Abstract}

Background: Hormonal contraceptives and hormone replacement therapies are classified as carcinogenic to humans (group 1) by the International Agency for Research on Cancer. We sought to estimate the proportion and total number of cancers attributable to the use of oral contraceptives and hormone therapy in Alberta in 2012.

Methods: Population attributable risks were used to estimate the proportion of attributable cases for each associated cancer site. Relative risk estimates were obtained from the most relevant and recent epidemiologic literature. Prevalences of the use of oral contraceptives and hormone therapy in Alberta were collected from Alberta's Tomorrow Project. Specific cancer incidence data were obtained from the Alberta Cancer Registry for the year 2012.

Results: Overall, $6.3 \%$ of breast cancers $(n=135)$ diagnosed in Alberta in 2012 were estimated to be attributable to the use of oral contraceptives, and the exposure potentially prevented about $57.3 \%$ of endometrial cancers $(n=276)$ and $29.1 \%$ of ovarian cancers ( $n=52$ ). About $15.5 \%$ of breast cancers $(n=258)$ and $8.9 \%$ of ovarian cancers $(n=13)$ were estimated to be attributable to the use of hormone therapy, whereas $11.3 \%$ of endometrial cancers $(n=48)$ were possibly prevented by the exposure.

Interpretation: Based on our estimates, oral contraceptive use resulted in a net protective effect among the cancer sites studied, thus reducing the cancer burden in Alberta in 2012. The use of hormone therapy was estimated to increase the cancer burden in the province, therefore the risk and benefit of hormone therapy should be carefully considered before use.

ex hormones are major causal factors for breast, endometrial and ovarian cancers. The International Agency for Research on Cancer classified combined estrogenprogestin hormonal contraceptives and menopausal hormone therapy as carcinogenic to humans (group 1) in 2007..$^{1}$ Oral contraceptives are associated with increased risk of breast cancer, particularly among current and recent users. ${ }^{1,2}$ Combined estrogen-progestin hormonal contraceptives decrease endometrial and ovarian cancer risks, and the protective effect persists after their use is stopped. ${ }^{1-4}$ Hormone therapy is associated with increased risk of ovarian and postmenopausal breast cancers, and decreased risk of endometrial cancer. ${ }^{5-7}$

Oral contraceptives are the most commonly used reversible contraception method in Canada. Based on the 2007-2009 and 2009-2011 Canadian Health Measurement Surveys, the prevalence of the current use of oral contraceptives was estimated to be $16 \%$ among women aged $15-49$ years, which is about 1.3 million women, and $99 \%$ of oral contraceptives used were estrogen-progestin combined formulations. ${ }^{8}$ The 2006/2007 National Population Health Survey showed that $13.7 \%$ of
Canadian women postmenopause and aged 50-69 years were currently taking or had recently taken hormone therapy. 9

Because many women rely on hormonal preparations for contraception or the management of their menopausal symptoms, assessing the risks and benefits of using hormonal preparations is important to minimize the potential cancer burdens associated with their use. In Alberta, breast, ovarian and endometrial cancer diagnoses account for more than $35 \%$ of all new cancers diagnosed among women each year. ${ }^{10-12}$ However, it is unknown what number and proportion of newly diagnosed cases are attributable to hormone use. The objective of this

\section{Competing interests: None declared.}

This article has been peer reviewed.

Correspondence to: Darren Brenner, darren.brenner@ albertahealthservices.ca

CMAJ Open 2016. DOI:10.9778/cmajo.20160046 
study was to estimate the proportions of breast, endometrial and ovarian cancers that were attributable to the use of oral contraceptives and hormone therapy in Alberta in 2012.

\section{Methods}

This manuscript is part of a series of exposure-specific manuscripts concerning the proportion of cancer attributable to modifiable lifestyle and environmental risk factors in the general population of Alberta. The methodologic framework for this series has been previously described. ${ }^{13}$

\section{Prevalence of hormone preparation exposure}

The prevalence of oral contraceptive and hormone therapy use in Alberta was estimated using data from Alberta's Tomorrow Project. At the time of data request, this large population-based cohort study recruited 30792 Albertans, including 18836 women aged 35-69 years, between 2000 and 2009. Prevalence estimation of oral contraceptive ever use was based on the participants' response to the question: "Have you ever taken birth control pills for any reason? (Do not include birth control pills prescribed for menopause)." Cohort participants also provided information on ever and current use of hormone therapies by responding to questions "Have you ever used female hormones for menopause, e.g., tablets, pills, a patch or creams prescribed by a doctor?" and "Are you currently using female hormones?" in the baseline questionnaire. Specific details concerning the preparations and regimens of hormone use were not provided.

\section{Population attributable fraction}

A systematic PubMed search was conducted to identify epidemiologic studies published up to June 2015 that reported risk estimates on breast, endometrial and ovarian cancer associated with oral contraceptive and hormone therapy use. Relevant relative risks (RRs) were abstracted and further screened. Risk estimates applicable to our prevalence data were selected for the population attributable risk ${ }^{14}$ calculation (Appendix 1, Supplementary Table 1 available at www.cmajopen.ca/content/
4/4/E754/suppl/DC1). Alberta's Tomorrow Project data did not allow current users of oral contraceptives to be distinguished from former users; therefore, the risk estimates comparing ever users with never users were used. For hormone therapies, the risk of ever use was analyzed separately from current use.

The population attributable risks associated with hormone preparation exposure for breast, endometrial and ovarian cancers were estimated using equation 1 :

Equation 1 Population attributable fraction $=P_{\mathrm{e}}(\mathrm{RR}-1) /\{1+$ $\left.\left[P_{\mathrm{e}}(\mathrm{RR}-1)\right]\right\}$

where $P_{\mathrm{e}}$ is the prevalence of ever or current hormone preparation users, RR is the relative risk of cancer for ever versus never users or current versus never users and $(R R-1)$ is the excess relative risk for oral contraceptive or hormone therapy use. This method was modelled after an analysis done by Parkin. ${ }^{15}$ Adopting this method allowed for a direct comparison between our results and Parkin's from the United Kingdom, which provided context to our findings.

To estimate $95 \%$ confidence intervals (CIs) around population attributable risk estimates, Monte Carlo simulation methods were used wherein the relative risk estimates were drawn from a $\log$ normal distribution, prevalence estimates from a binomial distribution and incidence estimates from a Poisson distribution. Parameters for the distributions were defined by reported point estimates and CIs. Ten thousand samples were drawn and the 2.5th and 97.5th percentiles of the resulting population attributable risk distribution were used as the lower and upper limits of a 95\% CI. Similar techniques were used by 2 previous studies that estimated population attributable risk. ${ }^{16,17}$ Wherever possible and appropriate, these estimations were performed for age groups. All analyses were conducted in $\mathrm{R}$ version 3.2.3 (The R Foundation for Statistical Computing).

\section{Excess attributable cancers}

The numbers of cancer cases attributable to oral contraceptive and hormone therapy use were estimated by combining

Table 1: Relative risks of cancers associated with use of oral contraceptives and hormone therapy

\begin{tabular}{|c|c|c|c|c|}
\hline Exposure & Cancer site & Detailed exposure & Risk estimate $(95 \% \mathrm{Cl})$ & Source \\
\hline \multirow[t]{3}{*}{ Oral contraceptives } & Breast & Ever use & $1.08(1.00-1.17)$ & Gierisch et al. $2013^{2}$ \\
\hline & Endometrium & Ever use & $0.57(0.43-0.77)$ & Gierisch et al. $2013^{2}$ \\
\hline & Ovary & Ever use & $0.73(0.66-0.81)$ & Havrilesky et al. $2013^{3}$ \\
\hline \multirow[t]{6}{*}{ Hormone therapy* } & Breast & Ever use & $1.39(1.12-1.72)$ & Shah et al. $2005^{5}$ \\
\hline & Breast & Current use & $1.66(1.58-1.75)$ & Beral $2003^{27}$ \\
\hline & Endometrium & Ever use & $0.78(0.72-0.86)$ & Brinton et al. $2014^{6}$ \\
\hline & Endometrium & Current use & $0.75(0.58-0.97)$ & Beral et al. $2005^{24}$ \\
\hline & Ovary & Ever use & $1.20(1.15-1.26)$ & Beral et al. $2015^{7}$ \\
\hline & Ovary & Current use & $1.41(1.32-1.50)$ & Beral et al. $2015^{7}$ \\
\hline
\end{tabular}


2012 Alberta cancer incidence data with population attributable risk estimates. Cancer incidence data were obtained from the Alberta Cancer Registry. The total proportion of cancer attributable to each of oral contraceptives and hormone therapies at each individual cancer site was estimated as the total number of excess attributable cases across age groups divided by the total number of observed cancers. Given that exposure data were collected between 2000 and 2009 , a latency period of 8 years was estimated, and age groups for cancer incidence data were lagged by 8 years (e.g., exposure data for age 35-44 yr corresponded to incidence data for age 43-52 yr) to reflect cancers diagnosed in 2012 that were caused by previous hormone exposure.

\section{Results}

Relative risks of cancer associated with contraceptive or hormone therapy use are shown in Table 1.

Alberta's Tomorrow Project maintained its response rates above $70 \%$. Participants from across Alberta were enrolled, and most of them (77\%) were from urban areas. ${ }^{18}$ The 2000 2009 survey results showed that $92.3 \%$ (95\% CI 91.7-93.0) of women aged 35-44 years had ever used or were currently using oral contraceptives, and the prevalence declined with increasing age (Table 2). About $60 \%$ of women aged 55 years and older have used hormone therapy (Table 2). Because hormone therapy is predominantly prescribed to women peri- or postmenopause, much smaller proportions of women younger than 54 years of age were given hormone therapies $(25.2 \%$ for age $45-54 \mathrm{yr}, 4.4 \%$ for age $35-44 \mathrm{yr}$ ). The proportion of women currently using hormone therapies peaked at the ages of 55-64 years, with $27.2 \%$ (95\% CI 25.9-28.5) of women reported as current users.

\begin{tabular}{|lcc|}
\hline $\begin{array}{l}\text { Table 2: Prevalence of oral contraceptive and hormone } \\
\text { therapy use in Alberta (Alberta's Tomorrow Project, 2000- } \\
\text { 2009) }\end{array}$ & $\begin{array}{c}\text { Prevalence } \\
(95 \% \text { Cl) }\end{array}$ \\
\hline \multirow{2}{*}{ Exposure } & Age, yr & $92.3(91.7-93.0)$ \\
\hline Oral contraceptives: ever use & $35-44$ & $91.1(90.4-91.8)$ \\
\cline { 2 - 3 } & $45-54$ & $85.5(84.5-86.6)$ \\
\cline { 2 - 3 } & $55-64$ & $67.6(65.3-69.9)$ \\
\hline Hormone therapy: ever use & $\geq 65$ & $4.4(3.9-4.9)$ \\
\cline { 2 - 3 } & $35-44$ & $25.2(24.2-26.3)$ \\
\cline { 2 - 3 } & $45-54$ & $60.3(58.9-61.7)$ \\
\cline { 2 - 3 } & $55-64$ & $60.5(58.1-62.9)$ \\
\hline Hormone therapy: current use & $35-44$ & $2.8(2.4-3.3)$ \\
\cline { 2 - 3 } & $45-54$ & $15.5(14.7-16.4)$ \\
\cline { 2 - 3 } & $55-64$ & $27.2(25.9-28.5)$ \\
\cline { 2 - 3 } & $\geq 65$ & $19.6(17.6-21.5)$ \\
\hline Note: Cl = confidence interval. & & \\
\hline
\end{tabular}

In 2012, 2128 cases of breast cancer were diagnosed in Alberta among women more than 43 years of age, and 135 of these cases $(6.3 \%)$ could be attributed to oral contraceptive use. A total of 661 cases of endometrial and ovarian cancer were diagnosed,; oral contraceptive use potentially prevented 276 endometrial cancers and 52 ovarian cancers, thus reducing the number of incident cases for these 2 cancer sites by almost half (49.6\%) (Table 3 and Table 4). When stratified by age (Table 3 and Appendix 1, Supplementary Table 2), because of the high prevalence among younger women, the highest attributable risk for breast cancer was found among the youngest age group (age $35-44 \mathrm{yr})$, with $7.0 \%(95 \% \mathrm{CI}=0.3-13.3)$ of cases $(n=32)$ attributable to oral contraceptive exposure. Women aged 45-54 yr benefited the most from oral contraceptive use, and it potentially prevented $63.4 \%(95 \% \mathrm{CI}=108.2-26.9 ; n=-116)$ of endometrial cancers and $32.6 \%$ (95\% CI $=45.2,21.5 ; n=$ $-15)$ of ovarian cancers. Overall, oral contraceptive use was estimated to attribute to 135 (1.8\%) cancers among 7681 observed incident cancer cases diagnosed in Alberta in 2012 and it potentially prevented 328 (4.3\%) cancer cases (Table 4), thus the exposure possibly reduced the cancer burden by 193 cases.

Our prevalence data showed that only 4.4\% (95\% CI 3.94.9) of women aged 35-44 years have used hormone therapy (Table 2), thus the population attributable risk was only assessed for women aged 45 years and older. In 2012, 1665 women aged 53 years and older had a diagnosis of breast cancer, and 258 and 199 of these cases could be attributed to hormone therapy ever and current use, respectively, representing $15.5 \%$ and $12.0 \%$ of observed breast cancer cases (Table 3 and Table 4). Population attributable risks for ovarian cancer were $8.9 \%(n=13)$ and $8.4 \%(n=12)$ for hormone therapy ever and current use (Table 3 and Table 4). Meanwhile, ever and current hormone therapy exposures potentially prevented 48 and 23 endometrial cancer cases, thus reducing the total observed cases by $11.3 \%$ and $5.4 \%$, respectively (Table 3 and Table 4). Among ever hormone therapy users, the attributable risk was higher among older women (age of exposure $\geq$ $55 \mathrm{yr}$ ) owing to higher prevalence rates (Table 2 and Table $3)$. For current hormone therapy users, higher attributable risk was seen among women aged 55-64 years as a result of a higher exposure rate (Table 3 and Appendix 1, Supplementary Table 2). Overall, hormone therapy current use was estimated to result in 211 attributable cases and 23 preventable cases (Table 4). Among ever users, 271 (3.5\%) cancer diagnoses, including 258 breast cancers and 13 ovarian cancers, were estimated to be attributable to the exposure among all 7681 cancer cases observed in Alberta in 2012, and 48 (0.6\%) postmenopausal endometrial cancers were potentially prevented (Table 4). Thus, hormone therapy exposure potentially increased the overall cancer burden by more than 200 cases in Alberta in 2012.

\section{Interpretation}

We quantified the population attributable risks of oral contraceptive and hormone therapy use on breast, endometrial and ovarian cancers among Albertan women aged 35-69 years 
in 2012. We estimated that 135 cases of cancer were attributable to oral contraceptives ever use and that 328 cases of cancer were potentially prevented by the exposure, resulting in a net protective effect. Ever use of hormone therapy was estimated to be associated with 271 newly diagnosed cancers, and it potentially prevented 48 cancers, thus increasing the overall cancer burden.

Compared with a similar study conducted in the UK in $2010,{ }^{15}$ we reported higher population attributable risks. Parkin estimated that the population attributable risks for oral contraceptive use were $1.1 \%,-16.9 \%$ and $-9.3 \%$ for breast, endometrial and ovarian cancers, respectively, ${ }^{15}$ compared with our estimates of $6.3 \%,-57.3 \%$ and $-29.1 \%$. Parkin also concluded that hormone therapy exposure increased the incidence of breast, endometrial and ovarian cancers by $3.2 \%$, $1.2 \%$ and $0.7 \%$, respectively, whereas our attributable risk estimations were $15.5 \%,-11.3 \%$ and $8.9 \%$. The disparities could partially be due to regional variations in hormone exposure. A previous review showed that $17 \%$ of Canadian women more than 40 years of age use oral contraceptives compared with $10 \%$ in the UK. ${ }^{19}$ In addition, inaccurate esti- mations of hormone prevalence could have further contributed to the disparity. The UK study obtained prevalence of hormone exposure on current users only, and the past exposures were estimated based on other published studies or were calculated using the difference of current users in population prevalence from one year to the next. ${ }^{15}$ Parkin indicated that the estimations of hormone past exposures were less accurate and were under estimated. Our results showed that $67.6 \%-92.3 \%$ of Albertan women reported oral contraceptive ever use and $4.4 \%-60.5 \%$ reported hormone therapy ever use. All Canadian national surveys conducted to date assessed current or recent hormone exposures only; however, a case-control study conducted in Alberta and British Columbia between 2005 and 2011 reported that $80 \%$ of participants in the control group aged 40-79 years had ever used oral contraceptives and $28 \%$ had ever used hormone therapy. ${ }^{20}$ The Alberta's Tomorrow Project cohort had a larger percentage of the cohort population with higher education and incomes compared with the national average. ${ }^{21}$ Studies have shown that women with less than post-secondary education were less likely to use contraception. ${ }^{22,23}$ The prevalence

Table 3: Observed cancer cases in Alberta (2012) and proportions attributable to use of oral contraceptives and hormone therapy

\begin{tabular}{|c|c|c|c|c|c|c|c|c|c|c|}
\hline \multirow[b]{2}{*}{$\begin{array}{l}\text { Age at } \\
\text { exposure, yr }\end{array}$} & \multirow[b]{2}{*}{$\begin{array}{c}\text { Age at } \\
\text { outcome, yr }\end{array}$} & \multicolumn{3}{|c|}{ Breast } & \multicolumn{3}{|c|}{ Endometrium } & \multicolumn{3}{|c|}{ Ovary } \\
\hline & & $\begin{array}{l}\text { Observed } \\
\text { cases }^{\star}\end{array}$ & PAR†, \% & EAC $\ddagger$ & $\begin{array}{c}\text { Observed } \\
\text { cases }^{*}\end{array}$ & $\mathrm{PAR}, \%$ & EAC & $\begin{array}{l}\text { Observed } \\
\text { cases }^{*}\end{array}$ & PAR, \% & EAC \\
\hline \multicolumn{11}{|c|}{ Oral contraceptives: ever use } \\
\hline $35-44$ & $43-52$ & 463 & 7.0 & 32 & 57 & -64.8 & -37 & 36 & -33.2 & -12 \\
\hline $45-54$ & $53-62$ & 584 & 6.9 & 40 & 183 & -63.4 & -116 & 46 & -32.6 & -15 \\
\hline $55-64$ & $63-72$ & 559 & 6.5 & 36 & 152 & -57.3 & -87 & 46 & -30.0 & -14 \\
\hline$\geq 65$ & $\geq 73$ & 522 & 5.2 & 27 & 90 & -40.4 & -36 & 51 & -22.3 & -11 \\
\hline Total & & 2128 & & 135 & 482 & & -276 & 179 & & -52 \\
\hline
\end{tabular}

Hormone therapy: ever use

\begin{tabular}{lccccccccccccc}
\hline $35-44$ & $43-52$ & & & & & & & & & & & & \\
\hline $45-54$ & $53-62$ & 584 & 9.0 & 52 & 183 & -5.9 & -11 & 46 & 4.8 & 2 \\
\hline $55-64$ & $63-72$ & 559 & 19.0 & 106 & 152 & -15.3 & -23 & 46 & 10.8 & 5 \\
\hline$\geq 65$ & $\geq 73$ & 522 & 19.1 & 100 & 90 & -15.3 & -14 & 51 & 10.8 & 6 \\
\hline Total & & 1665 & & 258 & 425 & & -48 & 143 & 13
\end{tabular}

Hormone therapy: current use

\begin{tabular}{|c|c|c|c|c|c|c|c|c|c|c|}
\hline $35-44$ & $43-52$ & & & & & & & & & \\
\hline $45-54$ & $53-62$ & 584 & 9.3 & 54 & 183 & -4 & -7 & 46 & 6.0 & 3 \\
\hline $55-64$ & $63-72$ & 559 & 15.2 & 85 & 152 & -7.3 & -11 & 46 & 10.0 & 5 \\
\hline$\geq 65$ & $\geq 73$ & 522 & 11.4 & 60 & 90 & -5.1 & -5 & 51 & 7.4 & 4 \\
\hline Total & & 1665 & & 199 & 425 & & -23 & 143 & & 12 \\
\hline
\end{tabular}

Note: $\mathrm{EAC}=$ excess attributable risk due to exposure, $\mathrm{PAR}=$ population attributable risk.

*The values represent the total number of cases of each cancer type diagnosed in 2012. For hormone therapy, only postmenopausal cases of cancer (cancers diagnosed at age $53 \mathrm{yr}$ and older) are included.

†Represents the proportion of cancer cases attributable to oral contraceptive ever use, hormone therapy ever use or hormone therapy current use. The negative values represent preventable proportions of cancer cases owing to protective effect.

†Represents the number of cases attributable to oral contraceptive ever use, hormone therapy ever use or hormone therapy current use. The negative values represent preventable cancer cases owing to protective effect. 
of hormone use in our study could have been overestimated because the surveyed population may have better access to drug coverage and is thus more likely to use hormone preparations.

We estimated that hormone therapy exposure had a protective effect on endometrial cancers $(-11.3 \%$ for ever use) whereas the UK study concluded that $1.2 \%$ of endometrial cancers were attributable to the exposure. ${ }^{15}$ This discrepancy was due to the regimen of hormones investigated by the 2 studies. The Alberta's Tomorrow Project survey did not provide details on hormone regimens, thus our analysis used RRs for continuous estrogen-progestin combined hormone therapy to be consistent with other cancer sites investigated. The UK study examined several regimens, including estrogen only, combined hormone therapy and tibolone. Evidence has shown that unopposed estrogen therapy and tibolone substantially increase endometrial cancer risk, ${ }^{24}$ whereas women who use continuous combined hormone therapy have lowered endometrial cancer risk. ${ }^{6}$

\section{Strengths and limitations}

A strength of our study was the inclusion of CIs around the population attributable risk estimates, thereby providing the precision of the estimates which was not done in the UK study. However, for estimates associated with ever oral contraceptive use and current exposure to hormone replacement therapies (Appendix 1, Supplementary Table 2), the wide confidence intervals highlight the lack of precision for those esti- mates. For example, although we estimated that 136 cases of breast cancer are attributable to ever using oral contraceptives, this estimate could range from 5 to 260 cases.

The restricted prevalence data available on current oral contraceptive exposure and cessation of hormone preparation use in Alberta created some limitations in this study. Increased risk of breast cancer was mostly found among current and recent users of oral contraceptives, ${ }^{1,2,25}$ and 10 years after cessation of use, the potential risk returned to baseline. ${ }^{1,2}$ Thus, the observed attributable risk for breast cancer related to ever using oral contraceptives was likely overestimated for women who stopped taking oral contraceptives more than 10 years ago. For endometrial and ovarian cancer, the estimate should be accurate because the protective effect of oral contraceptives on these cancers lasts for 20 years or more. ${ }^{1}$ In addition, because of limited availability of data, conducting sensitivity analyses to verify the impact of different latency periods on population attributable risk estimates was not possible. In a Canadian national study, where the population attributable risks of hormone therapy use on breast cancer were estimated over a 12 -year period, the attributable risk decreased from $11.5 \%$ in 2000 to $5.2 \%$ in 2006 because hormone therapy use decreased after the Women's Health Initiative Study was published in 2002. ${ }^{26}$ The same trend likely occurred in Alberta; however, because no Alberta-specific data concerning hormone use with this level of detail were available, we were unable to conduct these sensitivity analyses.

\begin{tabular}{|c|c|c|c|c|c|c|c|c|c|}
\hline \multirow[b]{2}{*}{ Cancer site } & \multicolumn{3}{|c|}{ Oral contraceptive: ever use } & \multicolumn{3}{|c|}{ Hormone therapy: ever use } & \multicolumn{3}{|c|}{ Hormone therapy: current use } \\
\hline & $\begin{array}{c}\text { Observed } \\
\text { casest }\end{array}$ & $\begin{array}{l}\text { Excess } \\
\text { attributable } \\
\text { cases } \ddagger\end{array}$ & $\begin{array}{c}\% \\
\text { Attributable§ }\end{array}$ & $\begin{array}{c}\text { Observed } \\
\text { cases }\end{array}$ & $\begin{array}{l}\text { Excess } \\
\text { attributable } \\
\text { cases }\end{array}$ & $\begin{array}{c}\% \\
\text { Attributable }\end{array}$ & $\begin{array}{l}\text { Observed } \\
\text { cases }\end{array}$ & $\begin{array}{l}\text { Excess } \\
\text { attributable } \\
\text { cases }\end{array}$ & $\begin{array}{c}\% \\
\text { Attributable }\end{array}$ \\
\hline Breast & 2128 & 135 & 6.3 & 1665 & 258 & 15.5 & 1665 & 199 & 12.0 \\
\hline Endometrium & 482 & -276 & -57.3 & 425 & -48 & -11.3 & 425 & -23 & -5.4 \\
\hline Ovary & 179 & -52 & -29.1 & 143 & 13 & 8.9 & 143 & 12 & 8.4 \\
\hline $\begin{array}{l}\text { All attributable } \\
\text { cancersf }\end{array}$ & 2128 & 135 & 6.3 & 1808 & 271 & 15.0 & 1808 & 211 & 11.7 \\
\hline All cancers ${ }^{* *}$ & 7681 & 135 & 1.8 & 7681 & 271 & 3.5 & 7681 & 211 & 2.7 \\
\hline $\begin{array}{l}\text { All } \\
\text { preventable } \\
\text { cancers†† }\end{array}$ & 661 & -328 & -49.6 & 425 & -48 & -11.3 & 425 & -23 & -5.4 \\
\hline All cancers & 7681 & -328 & -4.3 & 7681 & -48 & -0.6 & 7681 & -23 & -0.3 \\
\hline
\end{tabular}

*Data on prevalence of oral contraceptive and hormone therapy use are from the Alberta's Tomorrow Project.

†Number of observed cancer cases in Alberta in 2012 at individual cancer sites. Cancer incidence data obtained from the Alberta Cancer Registry. For hormone therapy, only postmenopausal cancer cases (cancers diagnosed at age $53 \mathrm{yr}$ and older) are included.

¥Number of cancer cases at individual cancer sites that can be attributed to oral contraceptive ever use, hormone therapy ever use or hormone therapy current use.

Negative values represent preventable cancer cases owing to the protective effect of oral contraceptive ever use, hormone therapy ever use or hormone therapy current use.

§Proportion of cancers at individual cancer sites attributable to oral contraceptive ever use, hormone therapy ever use or hormone therapy current use. Calculated as excess attributable cases/observed cases.

IRepresents all cancers with a known association with oral contraceptive ever use, hormone therapy ever use or hormone therapy current use, as listed in table.

${ }^{\star *}$ Represents all incident cancers in Alberta in 2012 in all age groups.

††Represents all preventable cancer cases associated with oral contraceptive ever use, hormone therapy ever use or hormone therapy current use, as listed in table. 


\section{Conclusion}

Although oral contraceptives and hormone therapy are both classified as carcinogens, the net effect of population attributable risks are different when multiple cancer sites are considered. Our analyses showed that the benefit of oral contraceptive use exceeds the potential risk among the cancer sites investigated because the number of cancers possibly reduced by oral contraceptive use was more than twice the number potentially associated with the exposure. Oral contraceptive use likely reduced the cancer burden in Alberta in 2012. In contrast, hormone therapy was estimated to increase the cancer burden in the province by about 200 excess cancer cases in 2012. The risks and benefits of hormone therapies should be carefully considered before their use.

\section{References}

1. IARC monographs on the evaluation of carcinogenic risks to bumans: volume 91: Combined estrogen-progestogen contraceptives and combined estrogen-progestogen menopausal therapy. Geneva: World Health Organization, International Agency for Research on Cancer; 2007:1-528.

2. Gierisch JM, Coeytaux RR, Urrutia, et al. Oral contraceptive use and risk of breast, cervical, colorectal, and endometrial cancers: a systematic review. Cancer Epidemiol Biomarkers Prev 2013;22:1931-43.

3. Havrilesky LJ, Moorman PG, Lowery WJ, et al. Oral contraceptive pills as primary prevention for ovarian cancer: a systematic review and meta-analysis. Obstet Gynecol 2013;122:139-47.

4. Bernstein L. The risk of breast, endometrial and ovarian cancer in users of hormonal preparations. Basic Clin Pharmacol Toxicol 2006;98:288-96.

5. Shah NR, Borenstein J, Dubois RW. Postmenopausal hormone therapy and breast cancer: a systematic review and meta-analysis. Menopause 2005;12:668-78.

6. Brinton LA, Felix AS. Menopausal hormone therapy and risk of endometrial cancer. 7 Steroid Biochem Mol Biol 2014;142:83-9.

7. Beral V, Gaitskell K, Hermon C, et al.; Collaborative group on epidemiological studies of ovarian cancer. Menopausal hormone use and ovarian cancer risk: individual participant meta-analysis of 52 epidemiological studies. Lancet 2015;385:1835-42.

8. Rotermann M, Dunn S, Black A. Oral contraceptive use among women aged 15 to 49: results from the Canadian Health Measures Survey. Health Rep 2015;26:21-8.

9. De P, Neutel CI, Olivotto I, et al. Breast cancer incidence and hormone replacement therapy in Canada. 7 Natl Cancer Inst 2010;102:1489-95.

10. Surveillance \& reporting: 2012 report on cancer statistics in Alberta. Edmonton: CancerControl AB, Alberta Health Services; 2015.

11. Cancer surveillance: 2010 report on cancer statistics in Alberta. Edmonton: Cancer Care, Alberta Health Services; 2012.

12. Cancer surveillance: 2008 report on cancer statistics in Alberta. Edmonton: Surveillance and Health Status Assessment, Alberta Health Services; 2010.

13. Grundy A, Frienenreich CM, Poirier AE, et al. A methodologic framework to evaluate the number of cancers attributable to lifestyle and environment in Alberta. CMA7 Open 2016;3:E471-8.

14. Levin ML. The occurrence of lung cancer in man. Acta Unio Int Contra Cancrum 1953;9:531-41.

15. Parkin DM. 10. Cancers attributable to exposure to hormones in the UK in 2010. Br 7 Cancer 2011;105(Suppl 2):S42-8.

16. Lee IM, Shiroma EJ, Lobelo F, et al. Effect of physical inactivity on major non-communicable diseases worldwide: an analysis of burden of disease and life expectancy. Lancet 2012;380:219-29.

17. Renehan AG, Soerjomataram I, Tyson M, et al. Incident cancer burden attributable to excess body mass index in 30 European countries. Int 7 Cancer 2010;126:692-702

18. Robson PJ, Solbak NM, Haig TR, et al. Design, methods, and demographics from phase I of Alberta's Tomorrow Project cohort: a prospective profile. CMA7 Open 2016;4:E515-25.
19. Allen RH, Cwiak CA, Kaunitz AM. Contraception in women over 40 years of age. CMA7 2013; 185:565-73.

20. Cook LS, Leung AC, Swenerton K, et al. Adult lifetime alcohol consumption and invasive epithelial ovarian cancer risk in a population-based case-control study. Gynecol Oncol 2016;140:277-84.

21. Bryant H, Robson PJ, Ullman R, et al. Population-based cohort development in Alberta, Canada: a feasibility study. Chronic Dis Can 2006;27:51-9.

22. Black A, Yang Q, Wu Wen S, et al. Contraceptive use among Canadian women of reproductive age: results of a national survey. 7 Obstet Gynaecol Can 2009;31:627-40

23. Frost JJ, Singh S, Finer LB. Factors associated with contraceptive use and nonuse, United States, 2004. Perspect Sex Reprod Health 2007;39:90-9.

24. Beral V, Bull D, Reeves G. Endometrial cancer and hormone-replacement therapy in the Million Women Study. Lancet 2005;365:1543-51.

25. Beaber EF, Buist DS, Barlow WE, et al. Recent oral contraceptive use by formulation and breast cancer risk among women 20 to 49 years of age. Cancer Res 2014;74:4078-89.

26. Neutel CI, Morrison H. Could recent decreases in breast cancer incidence really be due to lower HRT use? Trends in attributable risk for modifiable breast cancer risk factors in Canadian women. Canadian 7 Public Health 2010; 101:405-9.

27. Beral V. Breast cancer and hormone-replacement therapy in the Million Women Study. Lancet 2003;362:419-27.

Affiliations: Department of Cancer Epidemiology and Prevention Research (Grevers, Grundy, Poirier, Khandwala, Feldman, Friedenreich, Brenner), CancerControl Alberta, Alberta Health Services; Department of Oncology and Department of Community Health Sciences (Friedenreich, Brenner), Cumming School of Medicine, University of Calgary, Calgary, Alta.

Contributors: Christine Friedenreich and Darren Brenner were responsible for the study conception. Anne Grundy, Christine Friedenreich, Darren Brenner, Farah Khandwala, Xin Grevers, and Abbey Poirier contributed substantially to the study design and interpretation of the data. Farah Khandwala completed the analysis. Matthew Feldman and Anne Grundy were responsible for acquisition of the data. Abbey Poirier, Anne Grundy, Xin Grevers, Christine Friedenreich, Farah Khandwala, Matthew Feldman and Darren Brenner prepared the manuscript, gave final approval of this version to be published and agreed to be guarantors of the work.

Acknowledgements: This project was funded by the Alberta Cancer Prevention Legacy Fund. Dr. Christine Friedenreich is supported by an Alberta Innovates-Health Solutions Health Senior Scholar Award and the Alberta Cancer Foundation Weekend to End Women's Cancers Breast Cancer Chair at the University of Calgary. Dr. Darren Brenner is supported by a Capacity Development Award in Cancer Prevention from the Canadian Cancer Society Research Institute (703917). The authors thank Dr. Laura McDougall from the Alberta Cancer Prevention Legacy Fund for her support and guidance. The authors also thank Bethany Kaposhi and Lorraine Shack from the Alberta Cancer Registry for providing cancer incidence data. The authors are grateful for the prevalence data from Alberta's Tomorrow Project. Alberta's Tomorrow Project is only possible because of the commitment of its research participants, its staff and its funders: Alberta Cancer Foundation, Canadian Partnership Against Cancer, Alberta Cancer Prevention Legacy Fund (administered by Alberta Innovates - Health Solutions) and substantial in kind funding from Alberta Health Services. The views expressed herein represent the views of the author(s) and not of Alberta's Tomorrow Project or any of its funders.

Supplemental information: For reviewer comments and the original submission of this manuscript, please see www.cmajopen.ca/content/4/4/ E754/suppl/DC1 